\title{
The consequences of delaying insulin initiation in UK type 2 diabetes patients failing oral hyperglycaemic agents: a modelling study Gordon Goodall*1, Eric M Sarpong ${ }^{2}$, Clarice Hayes ${ }^{2}$ and William J Valentine ${ }^{3}$
}

\author{
Address: ${ }^{1}$ IMS Health, Allschwil, Switzerland, ${ }^{2}$ Global Health Outcomes, Eli Lilly \& Co., Indianapolis, USA and ${ }^{3}$ Ossian Health Economics and \\ Communications, Basel, Switzerland \\ Email: Gordon Goodall* - ggoodall@ch.imshealth.com; Eric M Sarpong - sarpong_eric@lilly.com; Clarice Hayes - hays_clarice@lilly.com; \\ William J Valentine - valentine@ossianconsulting.com \\ * Corresponding author
}

Published: 5 October 2009

BMC Endocrine Disorders 2009, 9:19 doi:10.1186/1472-6823-9-19

This article is available from: http://www.biomedcentral.com/1472-6823/9/19

(C) 2009 Goodall et al; licensee BioMed Central Ltd.

This is an Open Access article distributed under the terms of the Creative Commons Attribution License (http://creativecommons.org/licenses/by/2.0), which permits unrestricted use, distribution, and reproduction in any medium, provided the original work is properly cited.
Received: 15 September 2008

Accepted: 5 October 2009

\begin{abstract}
Background: Recent data have shown that type 2 diabetes patients in the UK delay initiating insulin on average for over II years after first being prescribed an oral medication. Using a published computer simulation model of diabetes we used UK-specific data to estimate the clinical consequences of immediately initiating insulin versus delaying initiation for periods in line with published estimates.

Methods: In the base case scenario simulated patients, with characteristics based on published UK data, were modelled as either initiating insulin immediately or delaying for 8 years. Clinical outcomes in terms of both life expectancy and quality-adjusted life expectancy and also diabetesrelated complications (cumulative incidence and time to onset) were projected over a 35 year time horizon. Treatment effects associated with insulin use were taken from published studies and sensitivity analyses were performed around time to initiation of insulin, insulin efficacies and hypoglycaemia utilities.

Results: For patients immediately initiating insulin there were increases in (undiscounted) life expectancy of 0.61 years and quality-adjusted life expectancy of 0.34 quality-adjusted life years versus delaying initiation for 8 years. There were also substantial reductions in cumulative incidence and time to onset of all diabetes-related complications with immediate versus delayed insulin initiation. Sensitivity analyses showed that a reduced delay in insulin initiation or change in insulin efficacy still demonstrated clinical benefits for immediate versus delayed initiation.

Conclusion: UK type 2 diabetes patients are at increased risk of a large number of diabetesrelated complications due to an unnecessary delay in insulin initiation. Despite clear guidelines recommending tight glycaemic control this failure to begin insulin therapy promptly is likely to result in needlessly reduced life expectancy and compromised quality of life.
\end{abstract}

\section{Background}

The global impact of type 2 diabetes on patients and healthcare systems is difficult to overstate given the sheer numbers of individuals with, and the chronic and perva- sive nature of, the condition. By 2025 it is estimated that 333 million adults will suffer from diabetes [1] and $90 \%$ of these will have type 2 diabetes. Economic consequences for healthcare payers are similarly dramatic with 
the most recent cost estimates in the US alone at $\$ 116$ billion for direct costs (pharmacy, hospitalisation, etc) and a further $\$ 58$ billion due to lost productivity as a direct consequence of complications arising from the disease [2]. There have been similar findings in Europe where the Cost of Diabetes in Europe (CODE-2) study estimated total annual expenditure for type 2 diabetes in eight countries [3]. Notably both studies highlighted the contribution of hospitalisation costs as a key driver (responsible for at least $50 \%$ of the total value) $[2,4]$ and the fact that the costs of treating patients with diabetes are higher than for those without $[2,5]$. In the UK alone, it is estimated that there are over 2.2 million individuals with diabetes and $5 \%$ of the total national healthcare budget (over $£ 1$ billion annually) is spent on treatment and management of the condition [6].

When managing type 2 diabetes the general focus is on achieving and maintaining good glycaemic control while minimising the potential for adverse events such as hypoglycaemia. The value of this approach has been shown from evidence gained in landmark clinical and epidemiological studies where the reduced incidence of micro- and macrovascular complications was apparent with intensive glycaemic control [7-14] and has further been confirmed in a published meta-analysis of observational studies [15]. To achieve these reductions in the incidence of complications, current UK guidelines from the National Institute for Health and Clinical Excellence (NICE) recommend target glycosylated haemoglobin (HbA1c) levels of between 6.5 and $7.5 \%$ (targets that are in line with guidance from other national and international bodies) [16]. Although this dogma has come under scrutiny and been challenged by some studies [17] it remains the central principal for the majority of treatment regimens [18] even if the initiation of insulin is often resisted by both patients and physicians [19].

Despite published guidance on the management of diabetes it is apparent that many patients fail to receive the appropriate standard of care (although the reasons are unclear and blame cannot be easily apportioned). The magnitude of this issue has been demonstrated by two studies examining type 2 diabetes management in the UK primary care setting $[20,21]$. In these retrospective cohort studies the authors found that not only were HbA1c measurements poorly recorded for the majority of patients, regardless of numbers of oral antidiabetic agents (OADs) prescribed, but even where data were available at least $40 \%$ of individuals failed to achieve a modest HbA1c target of $7.5 \%$ [21]. Despite this poor control the average time spent on monotherapy was 3.8 years and even after failing to achieve glycaemic control with two or more OADs the median time before commencing insulin therapy was 7.7 years from initiation of the final $\operatorname{OAD}[20,21]$.
This implies an average time to initiation of insulin of at least 11.5 years from initial diagnosis of type 2 diabetes. From the published data it is clear then that patients would not be maintaining their glycaemic control targets for a substantial proportion of this time. This has the obvious implication that patients are unnecessarily at an elevated risk of diabetes-related complications.

There are several interesting observations relating to the management of type 2 diabetes to come from these studies including: the infrequent measurement of HbA1c despite clear guidelines that this is the preferred measure of glycaemic control, the potential therapeutic benefits of multiple OADs treatment regimens, and the apparent reluctance of doctor or patient to initiate insulin. We have chosen to focus this investigation on the seemingly protracted delay to the initiation of insulin that UK patients are exposed to and it's potential consequences. Using a computer simulation model of long-term type 2 diabetes progression and based on published data the aim of this analysis was to compare the difference in projected lifetime clinical outcomes for patients immediately initiating versus delaying initiation of insulin.

\section{Methods \\ Model}

A brief overview of the CORE Diabetes Model is provided here, but a full description of the model has been previously published by Palmer et al. [22,23]. The model is a non-product-specific diabetes policy analysis tool that takes into account intensive or conventional insulin therapy, oral hypoglycaemic medications, screening and treatment strategies for micro-vascular complications, treatment strategies for end-stage complications and multi-factorial interventions. Disease progression is based on a series of inter-dependent sub-models that simulate progression of disease-related complications (angina, myocardial infarction, congestive heart failure, stroke, peripheral vascular disease, diabetic retinopathy, macula oedema, cataract, hypoglycaemia, ketoacidosis, lactic acidosis, nephropathy, end-stage renal disease, neuropathy, foot ulcer and amputation) as well as mortality from other causes. Each sub-model uses time, state and diabetes typedependent probabilities derived from published sources. The reliability of simulated outcomes has been tested, with results validated against those reported by clinical trials and epidemiological studies [23].

The model reports outcomes in terms of life expectancy (years), quality-adjusted life expectancy (quality-adjusted life years), cumulative incidence of complications and time free of complications. Quality of life outcomes are calculated using diabetes-specific state and event utilities from published studies [24-27]. 


\section{Hypothetical Treatment Progressions and Modelling Analyses}

The simulated treatment and patient inputs were based on reported data from two recent retrospective cohort studies of type 2 diabetes management in the UK [20,21]. In the base case analysis hypothetical UK patients were assigned to either insulin initiation in year 1 of the simulation, mimicking the administration of insulin following failure of OADs to maintain glycaemic control, or after 8 years, simulating the observed length of delay in line with published data [20]. Insulin efficacy in terms of effect on HbA1c levels, weight change and hypoglycaemia event rates were taken from a recent randomised clinical trial [28] (Table 1) as they reflect the observed change in HbA1c levels reported in the cohort study [20]. In order to simplify the analyses no change in other parameters (e.g. systolic blood pressure, serum lipids, etc.) were assumed for either treatment. In line with published evidence from the UKPDS HbA1c was assumed to increase by $0.15 \%$ in all years [9]. Simulations were performed over a 35 year time horizon to ensure all outcomes were accounted.

\section{Simulation Cohort and Reported Outcomes}

Patient characteristics were taken from published studies in the UK and are detailed in Table 2. Undiscounted life expectancy (years), quality-adjusted life expectancy (quality-adjusted life years), cumulative incidence of complications and time free of complications were calculated for each simulation and are reported where appropriate. Full results of all simulations including all outputs are available on request from the authors.

Statistical Methodology and One-Way Sensitivity Analyses For each simulation performed a cohort of 1,000 patients was run through the model 1,000 times to address firstorder uncertainty (random variation due to chance events). No statistical uncertainty around patient or treatment parameters was investigated due to the hypothetical nature of the analysis, however, one-way sensitivity analyses were performed to investigate the effects of assumptions on outcomes. In these scenarios individual aspects of the simulations were varied where: time to initiation of insulin was varied between 4 and 8 years; clinical benefits associated with insulin initiation from two alternative studies were accounted $[28,29]$; and no disutilities were accounted for hypoglycaemia events to highlight the effect of this on quality of life.

\section{Results \\ Main Findings}

When initiating insulin immediately, life expectancy was projected to increase by an average of 0.61 years $(\approx 7.5$ months) in comparison with a delay to insulin initiation of 8 years (11.40 versus 10.78 years) (Table 3 ). Survival curves show an obvious reduction in mortality after just 4 years of the simulation for those initiating insulin immediately versus delaying initiation, and this remains evident for the majority of the simulation period (Figure 1). There is also an improvement in quality-adjusted life expectancy where a benefit of 0.34 quality-adjusted life years (QALYs) is associated with immediate versus delayed initiation of insulin (7.53 versus 7.19 QALYs) (Table 3). This benefit is projected despite the additional hypoglycaemia risk individuals who immediately initiated insulin would experience in the first 8 years of the simulation versus those with delayed initiation (570 events per 100 patient years). Both of these clinical outcomes are driven by substantial reductions in the cumulative incidence and time to onset of most diabetes-related complications due to the improvements in glycaemic control associated with insulin administration (Table 4, Table 5).

\section{Sensitivity Analyses}

In all sensitivity analyses modelled improvements in clinical outcomes for immediate versus delayed initiation of insulin remained (Table 6). There were substantial benefits in life expectancy even when the time to initiation was reduced to 6 or 4 years. This difference in life expectancy for immediate versus delayed insulin initiation fell from 0.61 years in the base case to 0.57 and 0.48 years with a delay of 6 and 4 years, respectively. Interestingly there was little difference in quality-adjusted life expectancy for the same sensitivity analyses where it was reduced from 0.34 QALYs in the base case to 0.33 and 0.28 QALYs for a delay of 6 and 4 years, respectively. This was driven by the reduced effect of hypoglycaemia on quality of life offsetting the difference in incidence of complications.

Where different treatment effects associated with insulin were applied the magnitude of improvements in clinical

Table I: Treatment effects associated with insulin initiation

\begin{tabular}{lcccc}
\hline Scenario & HbAlc change (\%) & BMI change $\left(\mathbf{k g} / \mathbf{m}^{\mathbf{2}}\right)$ & Hypoglycaemia event rate (per I00 patient years) & Reference \\
\hline Base case & -1.30 & +1.53 & 570 & 310 \\
Higher HbAlc & -1.98 & +3.70 & 230 & {$[29]$} \\
Lower HbAlc & -0.80 & +1.90 & $28]$ & {$[28]$} \\
\hline
\end{tabular}

HbAlc -- glycosylated haemoglobin; BMI -- body mass index 
Table 2: Simulation cohort baseline characteristics

\begin{tabular}{lcc}
\hline Characteristic & Value & Reference \\
\hline Age (years) & 64.2 & {$[20]$} \\
Duration of diabetes (years) & 4 & {$[21]$} \\
Percentage male (\%) & 55.26 & {$[20]$} \\
\hline Clinical parameters & & \\
HbAlc (\%) & 8.16 & {$[20]$} \\
SBP (mmHg) & 141 & {$[30]$} \\
Total cholesterol (mg/dl) & 214.5 & {$[30]$} \\
HDL-cholesterol (mg/dl) & 42.9 & {$[30]$} \\
LDL-cholesterol (mg/dl) & 128.7 & {$[30]$} \\
Triglycerides (mg/dl) & 204.7 & {$[30]$} \\
BMI (kg/m²) & 30.1 & {$[20]$} \\
\hline Ethnicity & & \\
Proportion White (\%) & 82 & Assumed* \\
Proportion Black (\%) & 9 & Assumed* \\
Proportion Asian (\%) & 9 & Assumed* \\
\hline Comorbidities at baseline & & \\
Myocardial infarction (\%) & & \\
Peripheral vascular disease (\%) & 8.2 & {$[3 \mathrm{I}]$} \\
Stroke (\%) & 4.5 & {$[30]$} \\
Congestive heart failure (\%) & 6.6 & {$[30]$} \\
Microalbuminuria (\%) & 22.8 & {$[30]$} \\
End-stage renal disease (\%) & 0.7 & {$[31]$} \\
Background diabetic retinopathy (\%) & 17.7 & {$[31]$} \\
Neuropathy (\%) & $631]$ \\
\hline
\end{tabular}

HbAIc -- glycosylated haemoglobin; SBP -- systolic blood pressure; HDL -- high-density lipoprotein; LDL -- low-density lipoprotein; BMI - body mass index; * no data found and so assumed

outcomes was altered but the overall conclusions were the same. For an immediate versus 8 year delay in the initiation of insulin the difference in life expectancy was 0.82 and 0.37 years and difference in quality-adjusted life

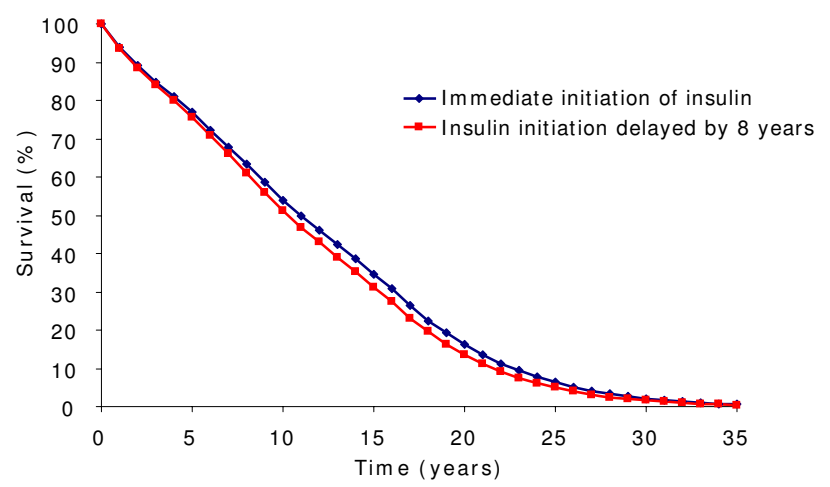

Figure I

Survival curve for simulated cohort initiating insulin immediately versus delaying for 8 years. expectancy was 0.63 and 0.24 QALYs for higher and lower estimates of HbA1c change, respectively.

If the disutility associated with hypoglycaemic events was eliminated there was an increase in the improvement in quality-adjusted life expectancy of 0.21 QALYs compared to the base case simulation ( 0.55 versus 0.34 QALYs) for immediate versus delayed initiation of insulin.

\section{Discussion}

Although it may be an unsurprising conclusion to draw that, improving glycaemic control earlier versus later leads to clinical benefits over time, the increase in mean life expectancy of over 7 months projected in this study is quite substantial. We have presented evidence here that in the UK setting, in line with published evidence on the average time spent with poorly or uncontrolled hyperglycaemia prior to initiating insulin, individuals are projected to experience improvements in life expectancy, quality-adjusted life expectancy and a reduced incidence and delayed onset of complications regardless of the delay to initiation and assumed efficacy of insulin.

Even though there is a notable risk of hypoglycaemia which would at least partly offset improvements in quality-adjusted life expectancy associated with insulin administration there were still substantial benefits for the immediate versus delayed initiation of insulin. By performing a sensitivity analysis where no quality of life disutility was accounted for hypoglycaemia events the effect on outcomes of this consequence of improved glycaemic control was evaluated. Overall the incidence of hypoglycaemia associated with insulin therapy led directly to a decrease in quality-adjusted life expectancy of 0.21 QALYs compared to the base case analysis ( 0.55 versus 0.34 QALYs).

Model outcomes have been presented here as undiscounted values to more clearly demonstrate the potential outcomes for immediate versus delayed initiation of insulin. Although NICE recommends a discount rate of 3.5\% per annum in the UK setting we have deliberately chosen not to conduct this study from an economic standpoint, but rather, relate only the potential clinical benefits that are foregone by delaying insulin initiation. However, as a matter of record, where outcomes were discounted the results for the base case showed a benefit for immediate versus delayed initiation of insulin in terms of life expectancy of 0.36 years ( 8.57 versus 8.20 years) and for qualityadjusted life expectancy of 0.18 QALYs (5.73 versus 5.55 QALYs). Although these discounted figures may not appear as dramatic as the undiscounted results they still represent substantial improvements that are in line or better than many health interventions seeking market approval. 
Table 3: Results of immediate initiation of insulin versus 8 year delay

\begin{tabular}{lccc}
\hline & Immediate Initiation & 8-year Delay & $10.78 \pm 0.24$ \\
\hline $\begin{array}{l}\text { Life expectancy (years) } \\
\text { difference }\end{array}$ & $11.40 \pm 0.25$ & 0.61 & $7.19 \pm 0.16$ \\
$\begin{array}{l}\text { Quality-adjusted life expectancy (QALYs) } \\
\text { difference }\end{array}$ & $7.53 \pm 0.17$ & 0.34 & \\
\hline
\end{tabular}

QALY -- quality-adjusted life year; discrepancies are due to rounding

As noted, this study makes no attempt to quantify the economic consequences of delaying insulin initiation. However there are likely to be direct medical cost savings associated with immediate initiation of insulin due to diabetes-related complications avoided. There are also other potential cost savings from a societal perspective, e.g. less need for carers, sustained productivity due to premature mortality or retirement avoided, etc. that are not accounted here.

Although the results from this modelling analysis unequivocally project improved outcomes for those initiating insulin and attaining HbA1c targets earlier than currently observed in the UK there are limitations to the study and these must be acknowledged. Most obviously this is a hypothetical modelling study and the outcomes are not based on randomised controlled clinical trial data (which would be ethically impossible to acquire). However, the inputs are based on recent real world data from the UK setting and where possible all data required to generate the analyses have been taken from the primary study publications $[20,21]$ and then supplemented with other UKspecific data $[30,31]$.

Additionally we have attempted to avoid bias by performing the analysis without a product-specific focus and it represents no particular commercial standpoint. In terms of the tool used to perform the analyses, the computer simulation model was developed as, and remains, a nonproduct-specific decision analysis tool that has been validated against a number of published clinical trials and shown to project robust and plausible outcomes [23]. In order to avoid unnecessary complexity and aid transparency the analysis was designed to allow minimal opportunities for bias or error (most inputs are unchanged between comparators) and was simplified where

Table 4: Cumulative incidence of diabetes-related complications

\begin{tabular}{|c|c|c|c|}
\hline & Immediate initiation & 8-year delay & Difference \\
\hline \multicolumn{4}{|l|}{ Complication } \\
\hline Congestive heart failure, onset (\%) & 29.22 & 30.08 & -0.87 \\
\hline Congestive heart failure, death (\%) & 26.58 & 26.26 & +0.31 \\
\hline Angina (\%) & 12.85 & 13.13 & -0.27 \\
\hline Myocardial infarction, event (\%) & 28.98 & 33.63 & -4.65 \\
\hline Myocardial infarction, death (\%) & 25.05 & 28.07 & -3.02 \\
\hline Stroke, event (\%) & 8.60 & 8.49 & +0.12 \\
\hline Stroke, death (\%) & 4.73 & 4.62 & +0.12 \\
\hline Background retinopathy (\%) & 14.08 & 17.70 & -3.62 \\
\hline Proliferative retinopathy (\%) & 0.91 & 1.22 & -0.31 \\
\hline Severe vision loss (\%) & 4.05 & 5.28 & -1.22 \\
\hline Macular oedema (\%) & 11.73 & $|4.8|$ & -3.09 \\
\hline Cataract (\%) & 6.77 & 7.45 & -0.68 \\
\hline Microalbuminuria (\%) & 18.66 & 23.21 & -4.56 \\
\hline Gross proteinuria (\%) & 3.97 & 5.17 & -1.20 \\
\hline End-stage renal disease (\%) & 0.59 & 0.75 & -0.16 \\
\hline Foot ulcer, first (\%) & 18.22 & 20.09 & -1.87 \\
\hline Foot ulcer, recurrence $(\%)$ & 18.62 & 20.54 & -1.92 \\
\hline First amputation (\%) & 4.37 & 4.72 & -0.35 \\
\hline Neuropathy, onset (\%) & 34.88 & 40.49 & $-5.6 \mid$ \\
\hline Peripheral vascular disease, onset (\%) & 13.80 & 15.90 & -2.10 \\
\hline
\end{tabular}


Table 5: Time to onset of diabetes-related complications (years)

\begin{tabular}{lccc}
\hline Complication & Immediate initiation & 8-year delay & Difference \\
\hline Any complications & 3.08 & 2.33 & 0.75 \\
\hline Congestive heart failure & 8.90 & 8.32 & 0.58 \\
Angina & 10.47 & 9.28 & 0.60 \\
Myocardial infarction & 10.04 & 9.86 & 0.76 \\
\hline Stroke & 10.43 & 7.68 & 0.57 \\
Background retinopathy & 8.48 & 10.67 & 0.80 \\
Proliferative retinopathy & 11.30 & 10.43 & 0.63 \\
Severe vision loss & 11.13 & 9.57 & 0.70 \\
Macula oedema & 10.48 & 10.17 & 0.91 \\
Cataract & 10.84 & 9.04 & \\
\hline Microalbuminuria & 10.03 & 10.51 & 10.76 \\
Gross proteinuria & 11.20 & 0.99 \\
End-stage renal disease & 11.37 & 9.73 & \\
\hline Foot ulcer & 10.44 & 10.57 &
\end{tabular}

necessary. For example, treatment effects associated with insulin in terms of changes to systolic blood pressure and serum lipids (total cholesterol, high- and low-density lipoprotein cholesterol and triglycerides) were not modelled. This was intended to both simplify and maintain a conservative approach as improvements in these parameters were likely to reduce cardiovascular outcomes and one would predict that this would favour the immediate versus delayed initiation of insulin scenario.

Another potential criticism of this analysis is that it does not account any insulin specific effects outside of change in HbA1c and risk of hypoglycaemia. Although there is a distinct absence of reliable data regarding safety issues with insulin, one area that merits specific attention is in individuals administering insulin subsequent to an MI event. The published epidemiological data from the DIGAMI-2 trial reported a significant increase in the cumulative endpoint of death, reinfarction and stroke (hazard ratio of 1.42) for those administering insulin subsequent to an MI event [32]. However, these results are in contrast to outcomes from the original DIGAMI study [33] and the two conclusions are challenging to resolve with each other. As the authors of the post-hoc analysis of the DIGAMI-2 trial themselves point out, there is the strong possibility that results may be confounded by unknown covariates, and in a complex disease such as diabetes this is a common concern. As there is a limited amount of data regarding this in the context of the analysis presented here no attempt has been made to account for a potential increase in further cardiovascular events following $\mathrm{MI}$ when administering insulin. It should be noted though

Table 6: Sensitivity analyses results

\begin{tabular}{|c|c|c|c|c|c|c|}
\hline & \multicolumn{3}{|c|}{ Life expectancy (years) } & \multicolumn{3}{|c|}{ Quality-adjusted life expectancy (QALY) } \\
\hline & $\begin{array}{l}\text { Immediate } \\
\text { Initiation }\end{array}$ & Delayed Initiation & Difference & $\begin{array}{l}\text { Immediate } \\
\text { Initiation }\end{array}$ & Delayed Initiation & Difference \\
\hline Base case & $11.40 \pm 0.25$ & $10.78 \pm 0.24$ & 0.61 & $7.53 \pm 0.17$ & $7.19 \pm 0.16$ & 0.34 \\
\hline $\begin{array}{l}\text { Initiation of insulin - } 6 \\
\text { year delay }\end{array}$ & $11.40 \pm 0.25$ & $10.83 \pm 0.25$ & 0.57 & $7.53 \pm 0.17$ & $7.20 \pm 0.17$ & 0.33 \\
\hline $\begin{array}{l}\text { Initiation of insulin - } 4 \\
\text { year delay }\end{array}$ & $11.40 \pm 0.25$ & $10.91 \pm 0.25$ & 0.48 & $7.53 \pm 0.17$ & $7.25 \pm 0.17$ & 0.28 \\
\hline Higher HbAlc change & $11.66 \pm 0.27$ & $10.85 \pm 0.23$ & 0.82 & $7.94 \pm 0.18$ & $7.31 \pm 0.16$ & 0.63 \\
\hline Lower $\mathrm{HbAlc}$ change & $\mid I .11 \pm 0.24$ & $10.74 \pm 0.25$ & 0.37 & $7.48 \pm 0.17$ & $7.23 \pm 0.17$ & 0.24 \\
\hline $\begin{array}{l}\text { No disutility for } \\
\text { hypoglycaemia }\end{array}$ & $11.40 \pm 0.25$ & $10.78 \pm 0.24$ & 0.61 & $7.88 \pm 0.17$ & $7.34 \pm 0.16$ & 0.55 \\
\hline
\end{tabular}

QALY -- quality-adjusted life expectancy; HbAlc -- glycosylated haemoglobin; discrepancies are due to rounding. 
that in the base case analysis the time to onset for a first MI event was greater than the delay to initiation of insulin and so for the majority of cases there would have been no difference in outcomes (i.e. both arms would have been administering insulin).

Additionally, a similar analysis could be carried out whereby glycaemic control is postulated to be better maintained by any manner (more appropriate prescription of OADs or other pharmaceutical interventions, compliance issues, patient education, physician support, etc.), however it was decided that with the published evidence available the use of insulin represented a more realistic scenario. It should be noted that the publications by Calvert and colleagues which prompted this analysis did not directly assess the make up of the OAD based regimens and whether there were any issue with patient compliance. However, glycaemic control measurements for individuals were often not recorded perhaps indicating a systematic failure to manage the patients condition regardless of the intervention used. Regardless of the specific management practice addressed in this context the results clearly highlight the potential benefits for type 2 diabetes patients in the UK who attain glycaemic control targets compared with the current "real world" observations.

By considering only insulin effects we excluded the possibility that patients may have been prescribed one of the new classes of diabetes interventions (DPP-IV inhibitor or GLP-1 agonist) prior to initiating insulin. As these new compounds reach the market and become available for prescription they may well be used prior to insulin initiation, however, the data available to us largely predated their use and so they were not considered in this analysis. Their use and effect on the glycaemic control of type 2 diabetes subjects in the UK remains to be demonstrated.

We have performed this study using a computer simulation model that incorporates risk formula generated from studies that demonstrated benefits associated with intensive glycaemic control in terms of hard clinical endpoints. Following on from these findings the attainment and maintenance of good glycaemic control as judged by HbA1c measurements is still recommended in most patient groups by national healthcare bodies. It has to be acknowledged though that some patients, such as the very elderly and seriously ill, are unlikely to realise the full long-term benefit of tight glycaemic control especially when associated with elevated risk of hypoglycaemia. There have also been publications questioning the benefits of intensive glycaemic control and the consequences for cardiovascular outcomes, such as the findings from the ACCORD study [17]. The cause of the increased mortality with intensive versus standard therapy in this study have still to be elucidated but they may indicate that aggressive titration to very low HbA1c levels is not appropriate for all (or indeed any) patients. Until there is an adequate explanation and association between the mortality risk and level of glycaemic control we are unable to effectively model this outcome with adequate understanding.

An issue not accounted in this study is the findings of an observational study by Bowker et al. [34] who reported a significantly higher rate of cancer-related mortality in patients exposed to sulfonylureas and insulin compared with patients exposed to metformin. This issue has received considerable attention recently with the publication of a study by Hemkens et al. [35] who reported a positive association between cancer incidence (with diagnosis of malignant neoplasm defined as the primary endpoint) and insulin glargine. However, the results were derived from studies conducted over a relatively short period of time (5 years), potentially suggesting that insulin (glargine) may accelerate the rate of development of existing tumours rather than stimulating malignant transformation and the formation of new ones [36]. Despite this concern the FDA has stated that variations in patient characteristics across treatment groups could have driven any difference in risk and has not acknowledged any confirmed link or advised any discontinuation of treatment [37]. With no firm evidence to link the use of insulin (or any other diabetes therapy) to increased cancer risk this has not been addressed in this analysis.

There are other implications that have not been addressed by this modelling analysis in relation to the management of diabetes patients that deserve further investigation. Although not reported in the two studies by Calvert and colleagues [20,21] there is accumulating evidence that type 2 diabetes patients are also poorly managed in terms of blood pressure and cholesterol levels [38-40]. It is highly likely that further clinical benefits not captured in this analysis could be realised if these additional patient management strategies were adhered to. Also, the similarities and differences between the levels of glycaemic control and time to initiation of insulin in the UK and other settings are unknown. It is not possible perhaps to translate these results directly to other countries but it would be surprising indeed if similar trends were not observed elsewhere and hence comparable outcomes.

It is known that progression to insulin therapy is often resisted by both patients and physicians [41]. The frequently cited reasons are both physical and psychological, for example a fear of injections, an inability to comply with the regimen or a feeling of failure in managing the disease so that insulin is now required for effective treatment. Patients themselves are also frequently unaware of the chronic and progressive nature of their condition and 
often do not understand the need for changes in therapies [42]. Regardless of the reasons for it, the consequences of failing to maintain glycaemic control are severe and this study clearly demonstrates the potential mortality and morbidity that could be avoided if guidelines and targets are adhered to.

\section{Conclusion}

The immediate versus delayed initiation of insulin is projected to lead to substantial improvements in clinical outcomes over patient lifetimes. Data from the UK have shown that patients may typically delay the initiation of insulin by around 8 years despite poor glycaemic control and as a consequence mean life expectancy is reduced by over 7 months for each patient.

\section{Competing interests}

GG and WJV are current or former employees of IMS Health who have received consultancy fees from Eli Lilly and Company.

ES and $\mathrm{CH}$ are employees of Eli Lilly and Company.

\section{Authors' contributions}

All authors have contributed to the manuscript. GG designed and performed the modelling analyses for the study and drafted the manuscript. ES, CH and WJV contributed to and critically appraised the manuscript. All coauthors have seen and approved the final version of the paper and have agreed to its submission for publication. No others have participated in the project who require recognition here.

\section{Acknowledgements}

The authors thank Eli Lilly and Company for the provision of an unrestricted grant to support this study.

\section{References}

I. Diabetes Atlas 2nd edition. Brussels: International Diabetes Federation; 2003.

2. American Diabetes Association: Economic costs of diabetes in the U.S. In 2007. Diabetes Care 2008, 3 I:596-6I5.

3. Jonsson B: Revealing the cost of Type II diabetes in Europe. Diabetologia 2002, 45:S5-12.

4. Williams R, Van Gaal L, Lucioni C: Assessing the impact of complications on the costs of Type II diabetes. Diabetologia 2002, 45:SI3-SI7.

5. Liebl A, Neiss A, Spannheimer A, Reitberger U, Wagner T, Gortz A: [Costs of type 2 diabetes in Germany. Results of the CODE2 study]. Dtsch Med Wochenschr 200I, 1 26:585-589.

6. Wanless D: Securing Our Health: Taking a Long-Term View Final Report. HM Treasury, London 2002 [http://webarchive.nation alarchives.gov.uk/+/http://www.hm-treas ury.gov.uConsultations and Legislation/wanless/ consult wanless final.cfm].

7. Ohkubo $\mathrm{Y}$, Kishikawa H, Araki E, Miyata T, Isami S, Motoyoshi S, Kojima $Y$, Furuyoshi N, Shichiri M: Intensive insulin therapy prevents the progression of diabetic microvascular complications in Japanese patients with non-insulin-dependent diabetes mellitus: a randomized prospective 6-year study. Diabetes Res Clin Pract 1995, 28:103-117.
8. The DCCT Research Group: The effect of intensive treatment of diabetes on the development and progression of longterm complications in insulin-dependent diabetes mellitus. N Engl J Med 1993, 329:977-986.

9. The UK Prospective Diabetes Study Group: Intensive blood-glucose control with sulphonylureas or insulin compared with conventional treatment and risk of complications in patients with type 2 diabetes (UKPDS 33). Lancet 1998, 352:837-853.

10. The UK Prospective Diabetes Study Group: Effect of intensive blood glucose control with metformin on complications in overweight patients with type 2 diabetes (UKPDS 34). Lancet 1998, 352:854-865.

II. The Diabetes Control and Complications Trial-Epidemiology of Diabetes Interventions and Complications Research Group: Retinopathy and nephropathy in patients with type I diabetes four years after a trial of intensive therapy. N Engl J Med 2000, 342:38I-389.

12. Lawson ML, Gerstein HC, Tsui E, Zinman B: Effect of intensive therapy on early macrovascular disease in young individuals with type I diabetes. A systematic review and meta-analysis. Diabetes Care 1999, 22(Suppl 2):B35-B39.

13. Stratton IM, Adler AI, Neil HA, Matthews DR, Manley SE, Cull CA, Hadden D, Turner RC, Holman RR: Association of glycaemia with macrovascular and microvascular complications of type 2 diabetes (UKPDS 35): prospective observational study. BMJ 2000, $321: 405-412$.

14. The ADVANCE Collaboration Group: Intensive blood glucose control and vascular outcomes in patients with type 2 diabetes. N Engl J Med 2008, 358:2560-2572.

15. Selvin E, Marinopoulos S, Berkenblit G, Rami T, Brancati FL, Powe NR, Golden SH: Meta-analysis: glycosylated hemoglobin and cardiovascular disease in diabetes mellitus. Ann Intern Med 2004, 1 41:42I-431.

16. American Diabetes Association: Standards of medical care in diabetes--2008. Diabetes Care 2008, 3 I (SuppI I):SI 2-S54.

17. Gerstein HC, Miller ME, Byington RP, Goff DC Jr, Bigger JT, Buse JB, Cushman WC, Genuth S, Ismail-Beigi F, Grimm RH Jr, Probstfield JL, Simons-Morton DG, Friedewald WT: Effects of intensive glucose lowering in type 2 diabetes. N Engl ] Med 2008, 358:2545-2559.

18. Nathan DM, Buse JB, Davidson MB, Ferrannini E, Holman RR, Sherwin $R$, Zinman B: Medical management of hyperglycemia in type 2 diabetes: a consensus algorithm for the initiation and adjustment of therapy: a consensus statement of the American Diabetes Association and the European Association for the Study of Diabetes. Diabetes Care 2009, 32:193-203.

19. Marrero DG: Overcoming patient barriers to initiating insulin therapy in type 2 diabetes mellitus. Clin Cornerstone 2007, 8:33-40.

20. Calvert MJ, McManus RJ, Freemantle N: Management of type 2 diabetes with multiple oral hypoglycaemic agents or insulin in primary care: retrospective cohort study. $\mathrm{Br} J$ Gen Pract 2007, 57:455-460.

21. Calvert MJ, McManus RJ, Freemantle N: The management of people with type 2 diabetes with hypoglycaemic agents in primary care: retrospective cohort study. Fam Pract 2007, 24:224-229.

22. Palmer AJ, Roze S, Valentine WJ, Minshall ME, Foos V, Lurati FM, Lammert M, Spinas GA: The CORE Diabetes Model: projecting long-term clinical outcomes, costs and cost-effectiveness of interventions in diabetes mellitus (types $I$ and 2) to support clinical and reimbursement mecision-making. Curr Med Res Opin 2004, 20:S5-S26.

23. Palmer AJ, Roze S, Valentine W, Minshall M, Foos V, Lurati F, Lammert M, Spinas GA: Validation of the CORE Diabetes Model against Epidemiological and Clinical Studies. Curr Med Res Opin 2004, 20:S27-S40.

24. Clarke P, Gray A, Holman R: Estimating utility values for health states of type 2 diabetic patients using the EQ-5D (UKPDS 62). Med Decis Making 2002, 22:340-349.

25. Mathers C, Vos T, Stevenson C: The burden of disease and injury in Australia. 1999 [http://www.aihw.gov.au/publications/phe/bdia/ bdia.pdf]. Australian Institute of Health and Welfare cat. no. PHE I7. Canberra: AlHW

26. Tengs TO, Wallace A: One thousand health-related quality-oflife estimates. Med Care 2000, 38:583-637. 
27. National Institute for Clinical Excellence: Technology appraisal guidance - No. 53. Guidance on the use of long-acting insulin analogues for the treatment of diabetes - insulin glargine. London 2002.

28. Holman RR, Thorne KI, Farmer AJ, Davies MJ, Keenan JF, Paul S, Levy JC: Addition of biphasic, prandial, or basal insulin to oral therapy in type 2 diabetes. N Engl J Med 2007, 357:1716-1730.

29. Yki-Jarvinen H, Juurinen L, Alvarsson M, Bystedt T, Caldwell I, Davies M, Lahdenpera S, Nijpels G, Vahatalo M: Initiate Insulin by Aggressive Titration and Education (INITIATE): a randomized study to compare initiation of insulin combination therapy in type 2 diabetic patients individually and in groups. Diabetes Care 2007, 30:1364-1369.

30. Cook MN, Girman CJ, Stein PP, Alexander CM: Initial monotherapy with either metformin or sulphonylureas often fails to achieve or maintain current glycaemic goals in patients with Type 2 diabetes in UK primary care. Diabet Med 2007, 24:350-358.

31. Rubino A, McQuay LJ, Gough SC, Kvasz M, Tennis P: Delayed initiation of subcutaneous insulin therapy after failure of oral glucose-lowering agents in patients with Type 2 diabetes: a population-based analysis in the UK. Diabet Med 2007, 24:1412-1418

32. Mellbin LG, Malmberg K, Waldenstrom A, Wedel H, Ryden L: Prognostic implications of hypoglycemic episodes during hospitalisation for myocardial infarction in patients with type 2 diabetes. A report from the DIGAMI 2 trial. E Heart J 2008, 29:166-176.

33. Malmberg K, Norhammar A, Wedel H, Ryden L: Glycometabolic state at admission: important risk marker of mortality in conventionally treated patients with diabetes mellitus and acute myocardial infarction: long-term results from the Diabetes and Insulin-Glucose Infusion in Acute Myocardial Infarction (DIGAMI) study. Circulation 1999, 99:2626-2632.

34. Bowker SL, Majumdar SR, Veugelers P, Johnson JA: Increased cancer-related mortality for patients with type 2 diabetes who use sulfonylureas or insulin. Diabetes Care 2006, 29:254-258.

35. Hemkens LG, Grouven U, Bender R, Gunster C, Gutschmidt S, Selke GW, Sawicki PT: Risk of malignancies in patients with diabetes treated with human insulin or insulin analogues: a cohort study. Diabetologia 2009, 52:1732-1744.

36. Smith $U$, Gale EA: Does diabetes therapy influence the risk of cancer? Diabetologia 2009, 52:1699-1708.

37. US Food and Drug Administration: Early Communication About Safety of Lantus (insulin glargine). [http:www.fda.goDrugDrugSafetPostmarketDrugSafetylnformationfo rPaentsandProvid erDrugSafetylnformationforHeathcareProfessionalucm 169722.htm] [Last accessed July 292009

38. Saydah SH, Fradkin J, Cowie CC: Poor control of risk factors for vascular disease among adults with previously diagnosed diabetes. JAMA 2004, 291:335-342.

39. Higgins GT, Khan J, Pearce IA: Glycaemic control and control of risk factors in diabetes patients in an ophthalmology clinic: what lessons have we learned from the UKPDS and DCCT studies? Acta Ophthalmol Scand 2007, 85:772-776.

40. Bebb C, Coupland C, Stewart J, Kendrick D, Madeley R, Sturrock N, Burden R: Practice and patient characteristics related to blood pressure in patients with type 2 diabetes in primary care: a cross-sectional study. Fam Pract 2007, 24:547-554.

41. Peyrot M, Rubin RR, Lauritzen T, Skovlund SE, Snoek FJ, Matthews $D R$, Landgraf $R$, Kleinebreil L: Resistance to insulin therapy among patients and providers: results of the cross-national Diabetes Attitudes, Wishes, and Needs (DAWN) study. Diabetes Care 2005, 28:2673-2679.

42. Phillips A: Starting patients on insulin therapy: diabetes nurse specialist views. Nurs Stand 2007, 2 I:35-40.

\section{Pre-publication history}

The pre-publication history for this paper can be accessed here:

http://www.biomedcentral.com/1472-6823/9/19/prepub
Publish with Bio Med Central and every scientist can read your work free of charge

"BioMed Central will be the most significant development for disseminating the results of biomedical research in our lifetime. "

Sir Paul Nurse, Cancer Research UK

Your research papers will be:

- available free of charge to the entire biomedical community

- peer reviewed and published immediately upon acceptance

- cited in PubMed and archived on PubMed Central

- yours - you keep the copyright 